\title{
Large-Scale Patterns in Hurricane-Driven Shoreline Change
}

\author{
Eli D. Lazarus
}

School of Earth and Ocean Sciences, Cardiff University, Cardiff, UK

Andrew D. Ashton

Department of Geology and Geophysics, Woods Hole Oceanographic Institution, Woods Hole, Massachusetts, USA

\author{
A. Brad Murray \\ Division of Earth and Ocean Sciences, Nicholas School of the Environment, Center for Nonlinear and Complex Systems \\ Duke University, Durham, North Carolina, USA
}

The effects of storm events on cross-shore beach profiles have been the subject of concerted examination by nearshore researchers for decades. Because these investigations typically span relatively short (less than a kilometer) shoreline reaches, alongshore patterns of storm-driven shoreline change at multikilometer scales remain poorly understood. Here we measure shoreline position from seven airborne lidar surveys of coastal topography, spanning 12 years (1996-2008), along a continuous $\sim 80 \mathrm{~km}$ stretch of the northern North Carolina Outer Banks, United States. Two of the lidar surveys were flown in the wakes of Hurricane Bonnie (1998) and Hurricane Floyd (1999), allowing a rare window into storm-related alongshore coastline changes at large scales. In power spectra of shoreline change variance and in calculations of plan view shoreline curvature, we find evidence of transient behaviors at relatively small alongshore scales (less than a kilometer) and an interesting combination of both transient and cumulative shoreline change patterns at larger scales $(1-10 \mathrm{~km})$. Large-scale plan view shoreline undulations grow in amplitude during the storm intervals we examined, possibly forced by a large-scale morphodynamic instability. Long-term (decadal) shoreline adjustments, however, trend in the opposite direction, with an overall diffusion or smoothing of shoreline shape at multiple-kilometer scales, probably due to gradients in alongshore sediment transport. Although storms can significantly reshape the coastline across a wide range of scales, those changes do not necessarily accumulate to patterns of long-term change.

Extreme Events and Natural Hazards: The Complexity Perspective Geophysical Monograph Series 196

(C) 2012. American Geophysical Union. All Rights Reserved.

10.1029/2011GM001074

\section{INTRODUCTION}

Visit a beach after the height of a storm, and evidence of the event is obvious. Dunes that had sloping toes have been carved into flat-faced escarpments, roads are undercut, and houses can even be found in the surf zone. Coastal geomorphology texts have long emphasized the rapid movement of sand offshore as the salient effect of storms on beaches [e.g., 
Davis, 1978; Carter, 1988; Davis and Fitzgerald, 2004] and with good reason: High winds and storm waves push a wedge of water onshore, allowing waves to reach more of the beach than under calm conditions. Persistent near-bed currents and breaking waves narrow the beach, transporting sediment offshore, building a sandbar. If storm surge elevates water levels high enough to submerge low-lying areas along the beach, sediment can be transported landward of the beach face and deposited behind the beach as overwash, removing that material from the immediate reach of the nearshore system [e.g., Godfrey and Godfrey, 1973; Komar, 1998].

But absent major overwashing, were you to return to the storm-battered beach in fair weather a few weeks later, you might be surprised to find those obvious signs of storm impact all but erased and the beach restored. Storm-driven formation of offshore bars, and the subsequent poststorm shoreward migration of those bars, is well documented [e.g., Davis and Fox, 1975; Birkemeier, 1979; Egense, 1989; Thom and Hall, 1991]. Sand removed from the beach during a storm event is stored offshore, typically in bars at the deep water margin of the storm surf zone, where the strength of the offshore current at the bed diminishes [Komar, 1998]. Then, in fair-weather conditions that tend to follow storms, long-period swell sweeps the sandbar shoreward, ultimately merging with the subaerial beach, resetting it to an effectively prestorm morphology [e.g., Zeigler et al., 1959; Sonu, 1973; Fucella and Dolan, 1996]. Timeaveraged images of the surf zone produce striking images of cyclical sandbar creation, migration, obliteration, and recreation with the passage of storm events [Holman and Stanley, 2007]. Looking along-coast, vehicle-mounted GPS shoreline surveys covering several tens of kilometers of coastline reveal that, even after large storm events, shoreline changes before and after a storm are effectively mirrored: coastal reaches that experience significant erosion see nearly equivalent magnitudes of accretion in the days and weeks following the storm event [List and Farris, 1999; List et al., 2006].

Although homes and coastal infrastructure face short-term hazards during a storm from both flooding and temporary erosion, significant long-term hazards for coastal dwellers and development arise from accumulated changes in the shoreline itself, manifesting as cross-shore changes in shoreline position on the order of tens to hundreds of meters (or more) over decades or longer. Multidecadal records of shoreline change show zones of cumulative aggradation and erosion that vary alongshore at scales on the order of kilometers [e.g., Schupp et al., 2006; North Carolina Division of Coastal Management, Oceanfront shorelines and setback: Interactive mapping, available at http://dcm2.enr.state.nc.us/Maps/ shoreline_mapintro.htm, accessed January 2011]. Shoreline change might be approximately net zero over storm-event time scales, but how do the magnitudes of storm-related shoreline variability compare to magnitudes of long-term, accumulated changes measured over a range of spatial scales? Do storms affect particular spatial scales more than others? What physical insights into coastal dynamics do we gain, or what new hypotheses can we generate, from comparing fair-weather and storm-related shoreline change over a range of spatial and temporal scales?

Focusing on the well-studied sandy barrier coastline of the northern North Carolina Outer Banks, United States (Figure 1), in this chapter, we build upon existing, fairweather analyses of shoreline change at multiple spatial and temporal scales [Tebbens et al., 2002; Lazarus and Murray, 2007; Lazarus et al., 2011] by introducing new analyses of two poststorm shorelines extracted from lidar surveys flown after Hurricane Bonnie (in 1998) and Hurricane Dennis and Hurricane Floyd (1999) (Table 1). We examine changes in shoreline position between different pairs of surveys. In some pairs, the second survey took place shortly after an extreme storm, and the change between surveys therefore reflects, in part, storm-driven changes. In other pairings, neither survey was affected by a recent extreme storm.
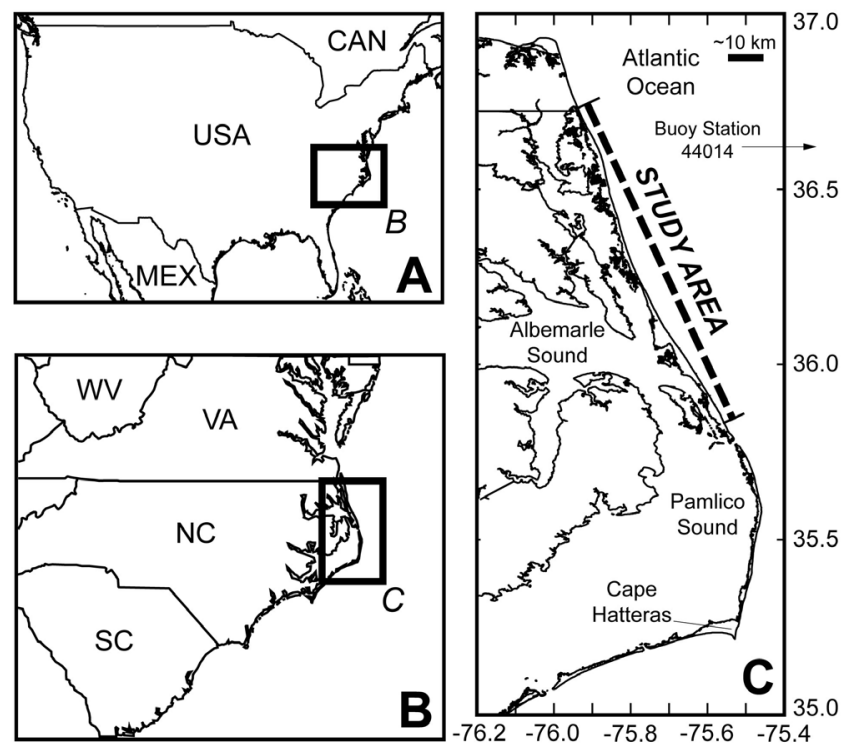

Figure 1. Our investigation focuses on approximately $80 \mathrm{~km}$ of uninterrupted coastline along the northern North Carolina Outer Banks, a sandy barrier island system on the U.S. Mid-Atlantic Seaboard (latitude/longitude in decimal degrees). National Buoy Data Center station 44014 (see Figure 5) is located at 36.611/74.836 , just out of the frame. Map data are courtesy of the NOAA coastline extractor, available at http://www.ngdc.noaa.gov/mgg/ coast/, accessed, February 2011.) 
Table 1. Lidar Surveys by Type (Fair Weather or Poststorm) and Date ${ }^{\mathrm{a}}$

\begin{tabular}{|c|c|c|c|c|}
\hline Survey Year & Fair Weather & Poststorm & Survey Date & Storm Date \\
\hline 1996 & $\mathrm{X}$ & & 9-12 Oct 1996 & \\
\hline 1997 & $\mathrm{X}$ & & 15-27 Sep 1997 & \\
\hline 1998 & & $\mathbf{X}$ & 1-7 Sep 1998 & 26 August \\
\hline 1999 & & $\mathbf{X}$ & 18 Sep to 6 Oct 1999 & 4 and 16 September \\
\hline 2004 & $\mathrm{X}$ & & 9-13 Jul 2004 & \\
\hline 2005 & $\mathrm{X}$ & & 1 Oct to 26 Nov 2005 & \\
\hline 2008 & $X$ & & 17-27 Mar 2008 & \\
\hline
\end{tabular}

${ }^{\text {a}}$ Original data, with survey metadata, available through the NOAA Coastal Services Center's Digital Coast portal (http://www.csc.noaa. gov/digitalcoast/data/coastallidar/details.html, accessed January 2009). Poststorm surveys are indicated in bold.

\section{SHORELINE CHANGE AND THE IMPORTANCE OF SPATIAL SCALE}

\subsection{Calculating Shoreline Change}

2.1.1. Extracting a shoreline from lidar data. Although the cost of long-distance aerial beach surveys makes their collection infrequent, airborne lidar maps coastal topography over long distances with high precision [e.g., Stockdon et al., 2002]. Here we extracted shorelines from the publicly available NOAA/U.S. Geological Survey/NASA lidar data sets listed in Table 1 (Digital Coast, NOAA Coastal Services Center (CSC), Coastal lidar, available at http://www.csc. noaa.gov/digitalcoast/data/coastallidar/details.html (hereinafter referred to as Digital Coast, NOAA CSC, Coastal lidar), accessed February 2007 and January 2009). To isolate a shoreline, we first converted raw $(x, y, z)$ point clouds $\left(0.25-8\right.$ points $\left.\mathrm{m}^{-1}\right)$ (Digital Coast, NOAA CSC, Coastal lidar, accessed July 2011) into $5 \mathrm{~m}$ gridded digital elevation models, registered to the 1988 North American Vertical Datum and projected to the universal transverse Mercator North American Datum 1983 Zone 18N ellipsoid. Shorelines stretching on the order of tens of kilometers can be defined at an elevation contour; we sampled the $1 \mathrm{~m}$ topographic contour, which lies within $0.5 \mathrm{~m}$ of the mean high-water line for this region of coast [Tebbens et al., 2002]. This contour retains fine-scale features in the beach while minimizing data artifacts from wave crests [Lazarus and Murray, 2007]. Airborne lidar data are typically vertically accurate to within 10-40 cm [Stockdon et al., 2002; Digital Coast, NOAA CSC, Coastal lidar, accessed July 2011]. With each shoreline registered and projected to the same reference frame, changes in shoreline position between two surveys can be determined by differencing the surveys.

The 1998 and 1999 lidar surveys were flown shortly after the passage of major storm events. On 26 August 1998, Hurricane Bonnie made landfall as a waning category 3 storm near Wilmington, North Carolina, south of our study area (National Hurricane Center, National Weather Service, NOAA, Archive of hurricane seasons, available at http:// www.nhc.noaa.gov/pastall.shtml (hereinafter referred to as National Hurricane Center, Archive of hurricane seasons), accessed February 2011); the lidar data were acquired between 1 and 7 September, 1998. In 1999, Hurricane Dennis (a weak but lingering storm that stalled offshore for several days) and Hurricane Floyd (category 2) made landfall in North Carolina on 4 and 16 September, respectively (National Hurricane Center, Archive of hurricane seasons, accessed February 2011); the lidar data we use here was acquired 18 September 1999 [White and Wang, 2003; Mitasova et al., 2005].

2.1.2. Examining shoreline change using wavelet analysis. We analyze the shoreline change signal using wavelets, which are scaled filter transforms that, when convolved with a signal, return coefficients constituting a spatially localized measure of signal variability at a given scale [Hubbard, 1996]. With the Wavelet Toolbox ${ }^{\text {TM }}$ in Matlab 2009b, we applied the basic Haar wavelet in a continuous wavelet transform. The Haar wavelet is a step function of the form

$$
\psi(x)=\left\{\begin{array}{cc}
1 & 0 \leq x<\frac{1}{2} \\
-1 & \frac{1}{2}<x \leq 1 \\
0 & \text { otherwise }
\end{array}\right.
$$

that is translated along the signal according to

$$
\psi_{j k}(x)=\psi\left(2^{j} x-k\right),
$$

where the scale exponent $j$ is a non-negative integer and $0 \leq$ $k \leq 2^{j}-1$. Because of its simple shape, the Haar wavelet is less sensitive to variability at fine spatial scales but useful for identifying lower-frequency signals. To mitigate edge effects at either end of the transform, we reflected the shoreline change signal several times and used a multiple of the signal 
[Nievergelt, 1999]. As an additional conservative step, we limited calculations to alongshore scales less than or equal to half the length of the original signal [Lazarus et al., 2011].

Squaring the wavelet transform coefficients produces a measure of signal variance, which, when averaged over the length of the signal, returns the mean shoreline variance at each wavelet scale. Averaging the wavelet transforms this way is equivalent to producing a Fourier transform. The typical utility of a wavelet transform is its preservation of spatial heterogeneities within a data series; by comparison, a Fourier transform assumes that each component wavelength exists through the entire domain of the data, washing out localized information. The rationale for using wavelets in a Fourier-like fashion is that a power spectrum provides a useful summary of how transform variance depends on scale, complimenting the scale-specific, spatial details contained in the full wavelet transform [Lazarus et al., 2011].

\subsection{Insights From Fair-Weather Shoreline Survey Comparisons}

2.2.1. Shoreline change characteristics at relatively small scales. A previous comparison of lidar-derived shoreline changes over 1 year, measured (in fair weather) for tens of kilometers alongshore, shows a log-log linear relationship between alongshore scale and the variance of shoreline change for alongshore scales spanning one order of magnitude, from approximately 100 to $1000 \mathrm{~m}$ [Tebbens et al., 2002]. Replicating this investigation in the same study area with different fair-weather, lidar-derived surveys of shoreline change ranging from 1 to 12 years, Lazarus et al. [2011] confirm that mean shoreline variance at scales 20-1000 m alongshore appear log-log linear (Figure 2a), suggesting that shoreline change follows a power law over these scales, the scaling exponent being a measure of the fractal roughness of the shoreline change pattern [Tebbens et al., 2002].

However, linearity in double-logarithmic plots, particularly over confined scales, is not definitive proof that a power law is the best descriptor for those data [e.g., Sornette, 2006]. Statistical measures of model uncertainty, such as the Akaike information criteria (AIC), help quantify how well different statistical distributions apply to data [Akaike, 1973; Burnham and Anderson, 2001, 2002]. Although the shoreline change power spectra that we investigate appear linear enough in log-log space to inspire comparison to a power law distribution, they are better described by lognormal, Weibull, and gamma functions that, with regard to AIC best fit, are statistically indistinguishable from each other [Lazarus et al., 2011]. (Locally, lognormal, Weibull, and gamma functions can resemble a power law.) Statistical fitting aside, the overall slope of the spectrum in Figure 2a indicates that the larger spatial scales exhibit greater change (variance), motivating an examination of scaling relationships at these more significant large scales.

2.2.2. Extending the power spectra. Focusing on the approximately straight line section of the power spectrum calls attention away from the spectrum of variance at larger alongshore scales. When the power spectrum is extended to alongshore scales greater than a kilometer, the data exhibit local
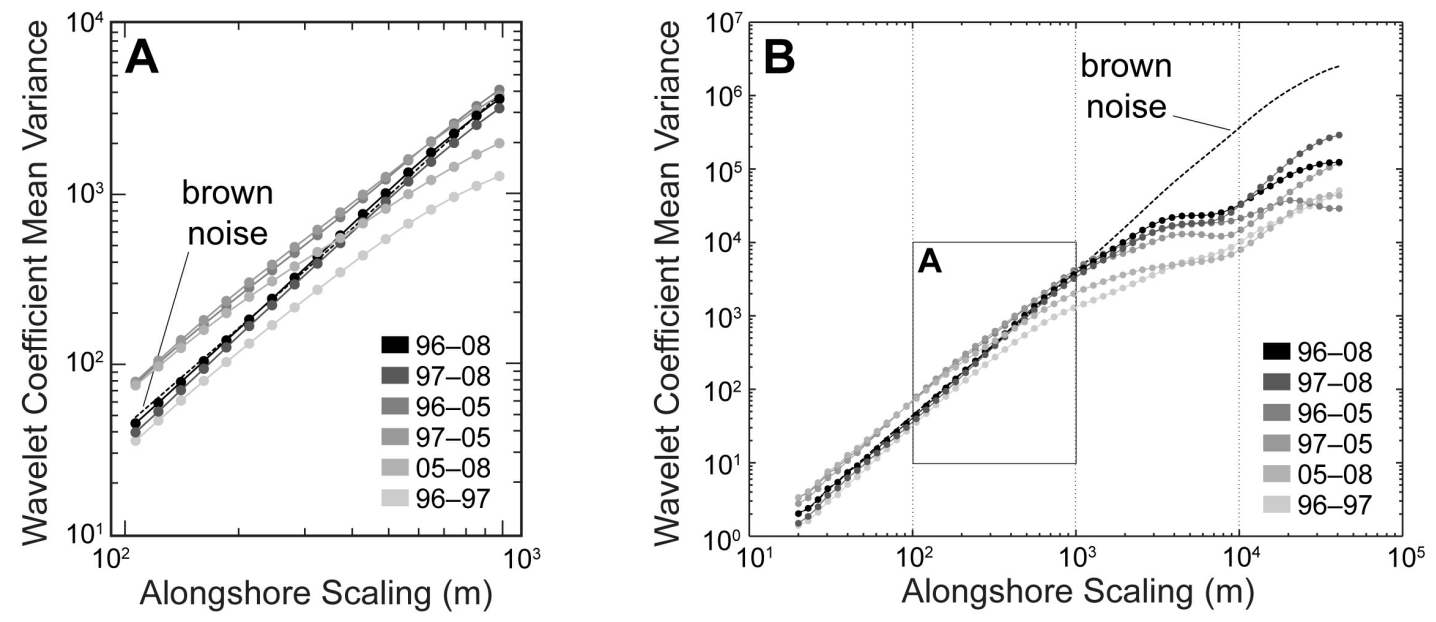

Figure 2. (a) Shoreline change power spectra, calculated for alongshore scales $10^{2}-10^{3} \mathrm{~m}$. (b) Shoreline change power spectra for a greater range of alongshore scales, with inset of Figure 2a delineated for comparison [after the work of Lazarus et al., 2011]. The brown noise signal is the integral of stochastically generated white noise and is characteristically scale-invariant. The local maxima evident in shoreline change variance spectra are therefore not artifacts of the wavelet processing technique. 
maxima (Figure 2b). These deviations from log-log linearity, occurring at scales between 1 and $10 \mathrm{~km}$, do not arise from finite domain effects or wavelet-processing artifacts (as the brown noise spectrum in Figure $2 \mathrm{~b}$ demonstrates), offering interesting potential clues about large-scale shoreline change [Lazarus et al., 2011]. Shoreline changes measured over longer temporal intervals ( $>3$ years) have greater variance magnitudes at large spatial scales (greater than a kilometer) than those measured over shorter time periods (1-3 years), in contrast with smaller scales (less than a kilometer), in which variance is similar across survey intervals (Figure 2b). At all scales above approximately $2 \mathrm{~km}$ (and below approximately $10 \mathrm{~km}$ ), the variance tends to increase, though the rate at which variance increases varies with scale and duration between surveys.

\subsection{Power Spectra for Poststorm Surveys}

Adding wavelet analyses of poststorm survey pairings to the fair-weather power spectra, we find that hurricane and nonhurricane pairings exhibit similar patterns of shoreline change variance (Figure 3). At small spatial scales, all the shoreline combinations share comparable magnitudes of variance, whether the duration between surveys is short or long and whether the comparison includes a poststorm survey or not. Similar to the fair-weather comparisons, survey pairings that include poststorm data return the greatest variance at larger spatial scales. Furthermore, the largest magnitudes of variance (the greatest first maxima) still occur in the pairs that span the most time: 1996-2008 and 1999-2004 (Figure 3).

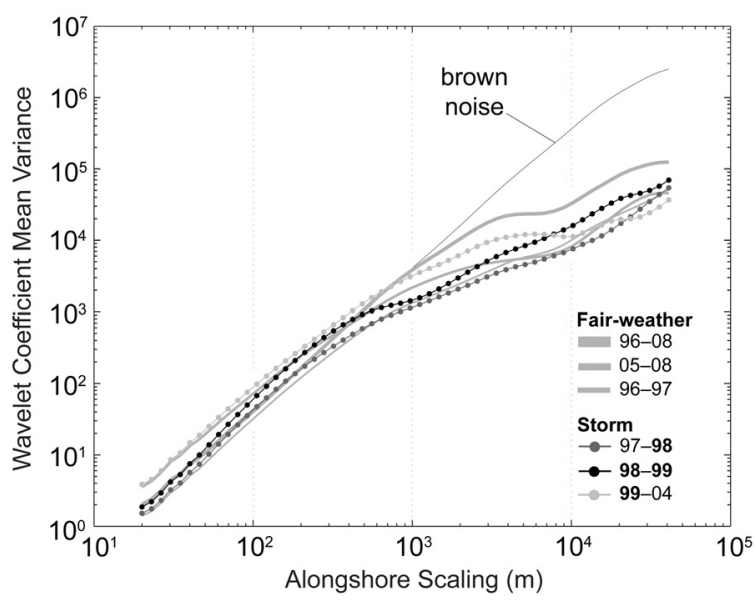

Figure 3. Shoreline change power spectra for storm years (lines with circles), compared to the 1,3 , and 12 year fair-weather spectra (gray lines, thin to thick, respectively) from Figure 2b. Storm years (1998 and 1999) are in bold.

\section{DYNAMICAL MECHANISMS OF SHORELINE CHANGE}

\subsection{Interpreting (Apparent) Power Laws}

We emphasize that these shoreline change power spectra (Figures 2 and 3) appear log-log linear but lack statistical signatures definitive enough to call them "power laws," to preempt the possible implication that power laws indicate de facto underlying scale-free dynamics.

Power laws are commonly interpreted to imply that because a quantity varies consistently between scales across a wide domain, the distribution reflects the dominance of a single dynamical process [e.g., Bak, 1996; Murray, 2007]. For many examples of self-similar patterns in nature, this interpretation of a single dominant process is likely appropriate, such as for certain dynamics of stick-slip earthquakes [e.g., Bak et al., 2002], fluvial dissection and channel branching [Pelletier, 1999; Jerolmack and Paola, 2007], and granular avalanches [Frette et al., 1996]. Power laws have been applied in coastal landscapes to describe fractal shoreline geometry [Mandelbrot, 1967], plan view crescentic patterns [Dolan and Ferm, 1968], and properties of cross-shore beach profiles [Southgate and Möller, 2000; Barton et al., 2003; Gunawardena et al., 2008].

But studies of shoreline change have demonstrated that distinct physical processes affect a sandy shoreline at differing spatial scales, contradicting the usual association of scale invariance with a particular dynamical interaction. Beach cusps can arise from swash zone feedback at scales of tens of meters [Werner and Fink, 1993; Coco et al., 2003]. Larger beach changes, spanning up to a few hundred meters alongshore, can result from surf zone currents interacting with and reorganizing sandbars [Ruessink et al., 2007]. Kilometerscale shoreline changes have been associated with wave propagation over larger-scale complex nearshore bathymetric features, such as persistent shore-oblique bar fields [McNinch, 2004; Schupp et al., 2006]. A unifying explanation for a seemingly consistent relationship between shoreline change variances across so many spatial scales therefore remains unclear, and the typical implications of a power law may not apply [e.g., Murray, 2007; Solow, 2005].

\subsection{Shoreline Behavior at Large Scales}

3.2.1. The role of alongshore sediment transport. Looking again at the shoreline change power spectra reminds us of three scale-related observations. First, the magnitude of the first maximum in shoreline change variance tends to increase with duration (for time scales $>1$ year). Second, the alongshore scale of the first maximum also increases with duration 
in a way that is consistent with a diffusional time/space scaling [Lazarus et al., 2011]. Third, variance at smaller scales, by comparison, exhibits little dependence on duration between surveys. Collectively, these analytical results frame two inferences: (1) A diffusional scaling relationship operating at multikilometer scales suggests a diffusional process different than processes affecting more transient shoreline changes at subkilometer scales. (2) The dynamics changing coastline shape over large spatial scales are principally responsible for the greatest amounts of shoreline change [ $\mathrm{Laz}-$ arus et al., 2011].

Along the northern North Carolina Outer Banks, between 1996 and 2005, at spatial scales greater than a kilometer, convex seaward promontories tended to erode landward, while concave seaward embayments tended to accrete [ $\mathrm{Laz}-$ arus and Murray, 2007]. One hypothesis for this relationship between large-scale, alongshore heterogeneous patterns of shoreline change and plan view shoreline shape is that, over decadal time scales and multikilometer spatial scales, cumulative shoreline change is driven by gradients in wave-forced alongshore sediment transport [Ashton and Murray, 2006b; Lazarus and Murray, 2007, 2011].

The flux of sediment alongshore, which is a function of the relative angle between the shoreline and incident waves, is maximized when the relative angle between incident deep water wave crests and the shoreline trend is approximately $45^{\circ}$ [Ashton et al., 2001; Falqués, 2003; Ashton and Murray, 2006a]. ("Deep water" in this context means seaward of the nearshore zone, or shoreface, in which seabed contours tend to approximately parallel the shoreline.) Given a plan view bump in a sandy shoreline, deep water waves with relative incident angles $<\sim 45^{\circ}$ set up a divergence of alongshore sediment at the convex seaward crest of the bump causing the bump to erode (diffuse), tending to maintain a shoreline that is relatively straight in plan view. Oppositely, when the deep water incident wave climate is dominated by high-angle waves (relative angles $>\sim 45^{\circ}$ ), convergence of alongshore sediment at the convex seaward crest of the bump (not necessarily a directional convergence but a flux convergence) causes the bump to accrete and plan view shoreline curvature to exaggerate [e.g., Ashton et al., 2001; Ashton and Murray, 2006a]. (Shoreline promontories need to reach a minimum alongshore scale before they are large enough to trigger the shoreline instability [Falqués and Calvete, 2005; List and Ashton, 2007].)

Theoretical modeling has demonstrated an emergent consequence of this antidiffusive behavior at the landform scale: As the plan view shoreline undulations grow to finite amplitudes, the largest-amplitude bumps begin to shade out their smaller-scale neighbors from the influence of high-angle waves, causing the neighboring perturbations to diffuse away and the dominant wavelength of the plan view shoreline to increase [Ashton et al., 2001; Ashton and Murray, 2006a; Coco and Murray, 2007]. Ultimately, the only parts of the shoreline that experience the net antidiffusive effect of the high-angle regional wave climate are the tips of the growing promontories. The rest of the coastline, either because of shoreline reorientation or wave shadowing from neighboring promontories, experiences a local wave climate that is dominated by low-angle waves [Ashton and Murray, 2006b]. Thus, even as the largest shoreline bumps advance seaward at their tips, diffusion along their flanks inhibits the growth of any new perturbations and reinforce a shoreline shape that is locally smooth in plan view [Lazarus and Murray, 2007].

However, no shoreline is completely straight (either as a consequence of geologic control, inheritance from previous configurations, or the development of subkilometer-scale undulations from other processes). Even if the long-term shoreline evolution trend is diffusive, occasional high-angle wave events can result in accentuation of existing shoreline curvature. If these high-angle waves occur during a storm, significant fluxes of alongshore sediment could lead to large gradients and a potentially measurable growth of shoreline instability.

\subsubsection{Hypothesis for shoreline instability during storm} events. A signature of these alongshore gradients would be a spatial correlation between shoreline change and plan view shoreline curvature. Here we define shoreline change as the cross-shore difference between two surveys of shoreline position and curvature as the second derivative of shoreline position. By convention, promontories are defined as having positive curvature and embayments as having negative curvature. The curvature data here are filtered with a $5 \mathrm{~km}$ Gaussian-type Hanning function to separate the low-frequency, multikilometer-scale shoreline shapes of interest from noisier high-frequency patterns [e.g., Lazarus and Murray, 2007].

Lazarus and Murray [2007] found a negative correlation between near-decadal shoreline change and shoreline curvature along a reach of the northern Outer Banks; erosion at promontories and accretion at embayments over scales greater than a kilometer is consistent with the diffusive smoothing effects of alongshore-transport gradients that result from a prevailing low-angle wave climate. The additional, poststorm surveys suggest that despite this long-term smoothing, shoreline behavior at those multikilometer scales can be locally antidiffusive during storms (Figure 4). While the general trend over the 12 years of data shown is diffusive, with gradual relaxation of curvature between 1996 and 2008 indicative of overall shoreline smoothing, the posthurricane shoreline curvatures express higher, more strongly peaked 

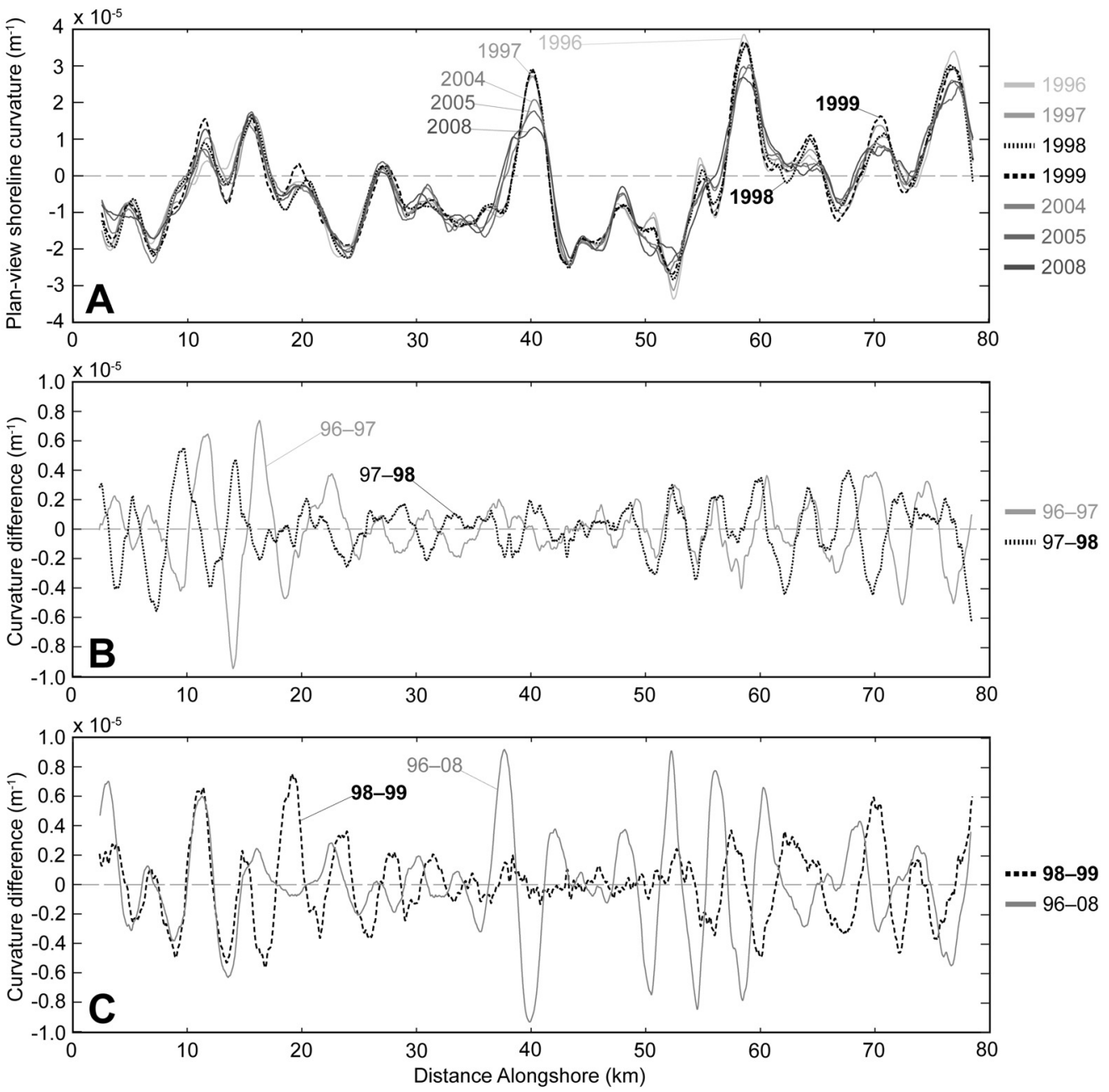

Figure 4. (a) Plan view shoreline curvature. Zones with positive (negative) curvature are subtle promontories (embayments). Hurricane events (bold) in 1998 (dotted) and 1999 (dashed) appear to have temporarily roughened the shoreline shape, which otherwise exhibits a long-term smoothing trend between 1996 and 2008. (b) Differences in curvatures between successive fair-weather and poststorm surveys and (c) poststorm surveys versus the long-term trend, both showing alongshore zones where the curvature differences are almost perfectly out of phase, consistent with temporary storm-related sharpening of plan view features that otherwise tend to smooth over time.

amplitudes at the major promontories and embayments (Figure 4).

Figure 4a shows that, at the $5 \mathrm{~km}$ scale, the general shape of shoreline curvature is consistent over the span of surveys plotted; the promontories and embayments do not appear to translate up and down the coastline over time. In Figures $4 \mathrm{~b}$ and $4 \mathrm{c}$, zones of curvature change (calculated by differencing the fair-weather and storm-related curvature signals) look almost perfectly out of phase in some stretches of coastline. Comparisons of fair-weather signals show certain promontories tending to blunt over time (e.g., between kilometers $10-20$ and 55-65), visible as a negative change in curvature at peaks of positive curvature and positive changes in curvature where the curvature is negative (both indicative of smoothing) (Figures 4a and 4c). At those same promontories, comparisons of storm-affected shorelines exhibit the opposite trend consistent with a sharpening of some of the plan view features (Figure $4 b$ ).

One possible explanation for storm-related magnification of large-scale undulations is that high-angle, highly energetic waves could have dominated during those storms. Deep water wave data (peak direction, height, and period), recorded offshore at the NOAA buoy station 44014, northeast of the Outer Banks (Figure 1) (National Data Buoy Center, 

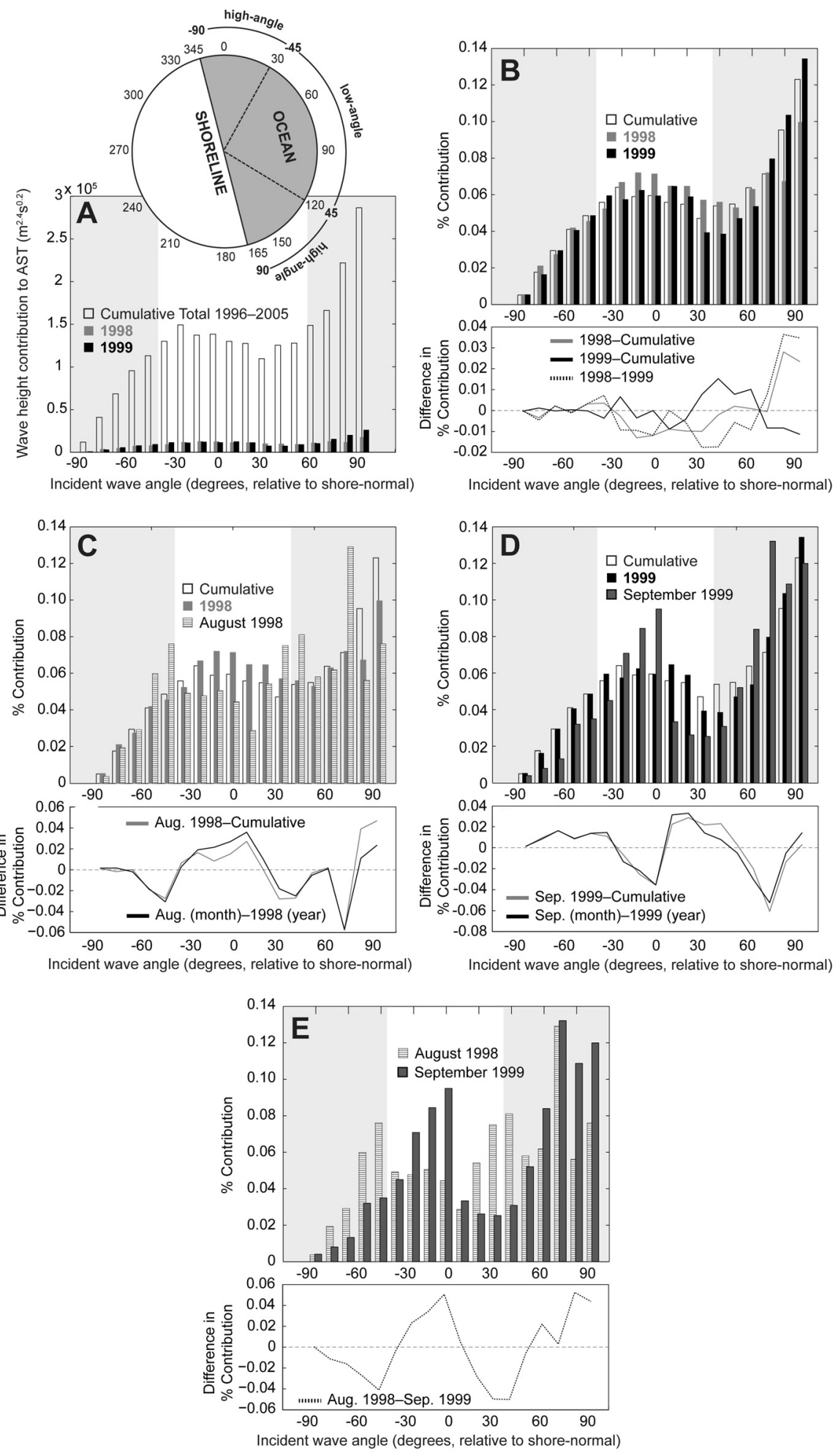

Figure 5 
Station 44014 (LLNR 550), available at http://www.ndbc. noaa.gov/station_page.php?station $=44014$, accessed January, 2011), can be converted into a directional spectrum of wave height contributions to alongshore sediment transport [e.g., Ashton and Murray, 2006b]. The near-decadal and annual (1998 and 1999) "effective" incident wave energy for this reach of shoreline have similar directional distributions, with deep water waves approaching from both nearly shoreorthogonal and high angles of incidence (Figures 5a and 5b). The distributions are skewed more to high-angle contributions, however, during the months in which hurricanes occurred (Figures 5c, 5d, and 5e). These wave data suggest that energetic influences from high angles in August, 1998, temporally associated with Hurricane Bonnie, were greater than the high-angle contributions during the 1998 year and the multiyear cumulative total. Equivalent data for September 1999 are similarly weighted toward comparatively greater contributions from high angles, likely capturing to some degree the passages of Hurricane Dennis and Hurricane Floyd. Though the relative differences between summed high-angle proportions may be small, previous modeling experiments have suggested that even slight predominance of wave energy from high angles can be enough to drive shoreline instability of the kind hypothesized here as even subtle large-scale curvature may be enough for gradients in alongshore sediment transport to be effective at changing shoreline shape [Ashton and Murray, 2006a, 2006b; Slott et al., 2006; Valvo et al., 2006, Lazarus and Murray, 2007].

\subsection{Controls on Long-Term Shoreline Evolution}

Admittedly, these incident wave distributions (Figure 5) can only serve as circumstantial evidence, limited as we are by the intervals (annual and longer) between lidar surveys; we cannot (and ought not) directly attribute all the shoreline changes reflected in the difference between the 1997 and 1998 lidar surveys, for example, to the effects of the Hurri- cane Bonnie event or are storm-driven waves and alongshore sediment flux the only forcing mechanisms affecting shoreline shape and evolution; interactions between incident wavefields and lithologic or bathymetric heterogeneities underlying the coastline (the coastal "geologic framework") surely influence nearshore hydrodynamics [Bender and Dean, 2003; Schupp et al., 2006; List et al., 2008; Benedet and List, 2008] and can also affect local supplies of beach sediment to effectively reinforce the amplitude of shoreline excursions in particular locations at particular scales [e.g., Valvo et al., 2006; Lazarus and Murray, 2011]. The longterm diffusional trend in shoreline change is therefore even more striking, considering the potential for storm-driven amplification of shoreline excursions (Figure 4) and the presence of known heterogeneities in the underlying physical framework [e.g., McNinch, 2004; Lazarus and Murray, 2011]. Although shoreline variability could be attributable to waves interacting with complex offshore bathymetry, studies generally suggest that shorelines attain undulating, but steady state shapes in response to bathymetric irregularities [e.g., Bender and Dean, 2003]. To date, no comparable hypothesis from the geologic-framework perspective (i.e., broadly applicable to a variety of locales) explains why erosion and accretion patterns should reverse in such similar fashion across so many scales for two independent forcing events and still produce the demonstrated trends in longterm shoreline change. However, wavefields interacting with complex offshore bathymetry in different ways during different storms (with different wave spectra) is most likely part of the fuller explanation of the curvatures changes exhibited in Figure 4, which shows shoreline responses that vary from one portion of the coastline to another and from one storm to another (contrasting Figures $4 \mathrm{~b}$ and $4 \mathrm{c}$ ).

Although the increase in variance with increasing scales that our shoreline-variance spectra exhibit may be unsurprising to nonlinear dynamicists, for the broad scientific community researching coastal, shoreline, and nearshore

\footnotetext{
Figure 5. (opposite) (a) Relative-angle schematic and incident deep water wave height contributions to alongshore sediment transport (similar to "wave energy") for the general shoreline orientation $\left(\mathrm{N} 15^{\circ} \mathrm{W}\right)$ of the northern Outer Banks. (Water depth at buoy station is $95 \mathrm{~m}$.) White bars show cumulative contributions for 1996-2005, relative to the annual contributions during 1998 (gray) and 1999 (black). (b) Data in Figure 5a in terms of percentage of total energy for the periods sampled to highlight relative directional contributions from high and low angles. Wave height contributions to alongshore sediment transport, as percentages by relative deep water angle of incidence, for (c) August 1998, compared to the cumulative total and the annual distribution for 1998, and (d) September 1999, compared to the cumulative total and the annual distribution for 1998. (e) Isolated comparison of August 1998 to September 1999. High-angle regions (approximately $<-45^{\circ}$ and $>45^{\circ}$ ) are shaded in gray in Figures $5 \mathrm{a}-5 \mathrm{e}$. Subplots in Figures $5 \mathrm{~b}-5 \mathrm{e}$ show differences in contributed percentages between distributions. Energy contribution from shore-incident high-angle waves is greater during the hurricane months of August 1998 and September 1999 than during the years of 1998 and 1999 and during the near-decadal period from 1996 to 2005. A wave-energy climate dominated by high-angle waves from the southeast is consistent with subtropical hurricane paths in this region (National Hurricane Center, Archive of hurricane seasons, accessed February 2011). (Buoy data are available at http://www.ndbc.noaa.gov/station_history.php? station=44014, accessed February 2011.)
} 
phenomena, it is unexpected to discover that changes caused by relatively well-studied processes at relatively small scales do not add up over time and that some poorly understood processes effective on larger scales apparently drive almost all of the long-term shoreline change. The coastal landscape evolves continuously, even during fairweather conditions; however, these forcing conditions are always changing, most dramatically during major storm events. Accordingly, debate persists over whether the dominant drivers of change in these landscapes of mobile sediment are cumulative or strictly episodic, especially in a physical setting where signs of episodic change can potentially get erased by other sediment-transport events or processes [e.g., Jerolmack and Paola, 2010].

The combination of (1) shoreline change variance at large spatial scales increasing with survey duration [Lazarus et al., 2011] and (2) the gradual relaxation (diffusion) of large-scale shoreline curvature suggests that the ongoing aggregation of shoreline position changes over longer time scales influences large-scale spatial change even more strongly than the punctuated, high-impact, antidiffusive changes wrought by strong forcing events like storms. The magnitudes of long-term (order 10 years), cumulative changes at large scales (greater than a kilometer) are still greater than the magnitudes of storm-related shoreline change at those spatial scales, at least for the hurricane events considered here (Figure 3), and simple as it may seem, the transience of small-scale changes in this system is not a trivial observation. The variance of changes at those smaller scales does not change with time; unlike the canonical variance envelope for a random walk, for example, we do not see an envelope of variability for those scales that widen with time. The lesson here is not that we expected small-scale features to aggregate into large-scale patterns and are surprised that they do not. Rather, the lesson is one familiar in complexity contexts but less so in many areas of physical science: If large-scale patterns of change are the hierarchical scale of interest, these data we analyze emphasize the importance of measuring coastal change with methods that record the dynamics that emerge at those scales because extrapolation from smaller scales may not be viable.

\section{CONCLUSIONS}

Our analysis of power spectra demonstrates that, along the North Carolina Outer Banks coast, the scaling dependencies of shoreline change variance induced by extreme storms do not appear to differ significantly from those of nonstorm intervals, at least at alongshore scales of a few kilometers and smaller. However, the variance of shoreline change is a squared quantity and therefore does not retain the directional sign of change (positive or negative). Examining large-scale changes in shoreline curvature reveals that the storm-related changes can be the opposite of long-term patterns, in the sense that during storms, the plan view coastline becomes rougher in some sections of the coastline, while the longerterm change data indicate an overall smoothing trend. Measuring both persistent, cumulative coastal changes and more ephemeral shoreline change effects of storms at large scales, and subsequently managing those changes, may require a different set of observational strategies [e.g., McNinch, 2007] than those designed to capture smaller-scale and typically ephemeral beach behaviors.

Acknowledgments. Our thanks to the National Science Foundation (grants EAR-04-44792 and EPS-0904155), the Joint Airborne Lidar Bathymetry Technical Center for Expertise (JALBTCX), the 2010 Chapman Conference on Complexity and Extreme Events in Geosciences, and the editors of this monograph.

\section{REFERENCES}

Akaike, H. (1973), Information theory as an extension of the maximum likelihood principle, in Second International Symposium on Information Theory, edited by B. N. Petrov and F. Csaki, pp. 267-281, Akad. Kiadó, Budapest, Hungary.

Ashton, A. D., and A. B. Murray (2006a), High-angle wave instability and emergent shoreline shapes: 1 . Modeling of sand waves, flying spits, and capes, J. Geophys. Res., 111, F04011, doi:10. 1029/2005JF000422.

Ashton, A. D., and A. B. Murray (2006b), High-angle wave instability and emergent shoreline shapes: 2 . Wave climate analysis and comparisons to nature, J. Geophys. Res., 111, F04012, doi:10.1029/2005JF000423.

Ashton, A. D., A. B. Murray, and O. Arnoult (2001), Formation of coastline features by large-scale instabilities induced by highangle waves, Nature, 414, 296-300.

Bak, P. (1996), How Nature Works: The Science of Self-Organized Criticality, 226 pp., Springer, New York.

Bak, P., K. Christensen, L. Danon, and T. Scanlon (2002), Unified scaling law for earthquakes, Phys. Rev. Lett., 88(17), 178501, doi:10.1103/PhysRevLett.88.178501.

Barton, C., J. S. Dismukes, and R. A. Morton (2003), Complexity analysis of the change in shoreline position at Duck, NC, in Coastal Sediments 2003 [CD-ROM], Am. Soc. of Civ. Eng., Reston, Va.

Bender, C. J., and R. G. Dean (2003), Wave field modification by bathymetric anomalies and resulting shoreline changes: A review with recent results, Coastal Eng., 49, 125-153.

Benedet, L., and J. H. List (2008), Evaluation of the physical process controlling beach changes adjacent to nearshore dredge pits, Coastal Eng., 55(12), 1224-1236.

Birkemeier, W. A. (1979), The effects of the 19 December 1977 coastal storm on beaches in North Carolina and New Jersey, Shore Beach, 47(1), 7-15. 
Burnham, K. P., and D. R. Anderson (2001), Kullback-Leibler information as a basis for strong inference in ecological studies, Wildlife Res., 28, 111-119.

Burnham, K. P., and D. R. Anderson (2002), Model Selection and Multimodel Inference, 496 pp., Springer, New York.

Carter, R. W. G. (1988), Coastal Environments, 617 pp., Academic Press, San Diego, Calif.

Coco, G., and A. B. Murray (2007), Patterns in the sand: From forcing templates to self-organization, Geomorphology, 91, 271-290.

Coco, G., T. K. Burnet, B. T. Werner, and S. Elgar (2003), Test of self-organization in beach cusp formation, J. Geophys. Res., 108 (C3), 3101, doi:10.1029/2002JC001496.

Davis, R. A., Jr. (Ed.) (1978), Coastal Sedimentary Environments, 420 pp., Springer, New York.

Davis, R. A., Jr., and D. M. Fitzgerald (2004), Beaches and Coasts, 419 pp., Blackwell, Malden, Mass.

Davis, R. A., Jr., and W. T. Fox (1975), Process-response mechanisms in beach and nearshore sedimentation, I, Mustang Island, Texas, J. Sediment. Petrol., 45, 852-865.

Dolan, R., and J. C. Ferm (1968), Crescentic landforms along the Atlantic Coast of the United States, Science, 159, 627-629.

Egense, A. K. (1989), Southern California beach changes in response to extraordinary storm, Shore Beach, 57(4), 14-17.

Falqués, A. (2003), On the diffusivity in coastline dynamics, Geophys. Res. Lett., 30(21), 2119, doi:10.1029/2003GL017760.

Falqués, A., and D. Calvete (2005), Large-scale dynamics of sandy coastlines: Diffusivity and instability, J. Geophys. Res., 110, C03007, doi:10.1029/2004JC002587.

Frette, V., K. Christensen, A. Malthe-Sørenssen, J. Feder, T. Jøssang, and P. Meakin (1996), Avalanche dynamics in a pile of rice, Nature, 379, 49-52.

Fucella, J. E., and R. Dolan (1996), Magnitude of beach disturbance during northeast storms, J. Coastal Res., 12, 420-429.

Godfrey, P. J., and M. M. Godfrey (1973), Comparison of ecological and geomorphic interactions between altered and unaltered barrier island systems in North Carolina, in Coastal Geomorphology, edited by D. R. Coates, pp. 239-258, State Univ. of N. Y., Binghamton.

Gunawardena, Y., S. Ilic, H. N. Southgate, and H. Pinkerton (2008), Analysis of the spatio-temporal behavior of beach morphology at Duck using fractal methods, Mar. Geol., 252, 38-49.

Holman, R. A., and J. Stanley (2007), The history and technical capabilities of Argus, Coastal Eng., 54, 477-491.

Hubbard, B. B. (1996), The World According to Wavelets: The Story of a Mathematical Technique in the Making, 264 pp., A. K. Peters, Wellesley, Mass.

Jerolmack, D. J., and C. Paola (2007), Complexity in a cellular model of river avulsion, Geomorphology, 91, 259-270.

Jerolmack, D. J., and C. Paola (2010), Shredding of environmental signals by sediment transport, Geophys. Res. Lett., 37, L19401, doi:10.1029/2010GL044638.

Komar, P. D. (1998), Beach Processes and Sedimentation, 2nd ed., 544 pp., Prentice-Hall, Upper Saddle River, N. J.
Lazarus, E. D., and A. B. Murray (2007), Process signatures in regional patterns of shoreline change on annual to decadal time scales, Geophys. Res. Lett., 34, L19402, doi:10.1029/2007GL 031047.

Lazarus, E. D., and A. B. Murray (2011), An integrated hypothesis for regional patterns of shoreline change along the northern North Carolina Outer Banks, U.S.A., Mar. Geol., 281(1-4), 85-90, doi:10.1016/j.margeo.2011.02.002.

Lazarus, E. D., A. Ashton, A. B. Murray, S. Tebbens, and S. Burroughs (2011), Cumulative versus transient shoreline change: Dependencies on temporal and spatial scale, J. Geophys. Res., 116, F02014, doi:10.1029/2010JF001835.

List, J. H., and A. Ashton (2007), A circulation modeling approach for evaluating the conditions for shoreline instabilities, in Coastal Sediments '07, edited by N. C. Kraus and J. D. Rosati, pp. 327340, Am. Soc. Civ. Eng., Reston, Va.

List, J. H., and A. S. Farris (1999), Large-scale shoreline response to storms and fair weather, in Coastal Sediments '99, edited by N. C. Kraus and W. G. McDougal, pp. 1324-1338, Am. Soc. of Civ. Eng., Reston, Va.

List, J. H., A. Farris, and C. Sullivan (2006), Reversing storm hotspots on sandy beaches: Spatial and temporal characteristics, Mar. Geol., 226, 261-279.

List, J. H., L. Benedet, D. M. Hanes, and P. Ruggiero (2008), Understanding differences between DELFT3D and empirical predictions of alongshore sediment transport gradients, in Coastal Engineering 2008: Proceedings of the 31st International Conference, edited by J. M. Smith, pp. 1864-1875, World Sci., London, U. K., doi:10.1142/9789814277426_0154.

Mandelbrot, B. (1967), How long is the coast of Britain? Statistical self-similarity and fractional dimension, Science, 156, 636-638.

McNinch, J. E. (2004), Geologic control in the nearshore: Shoreoblique sandbars and shoreline erosional hotspots, Mid-Atlantic Bight, USA, Mar. Geol., 211(1-2), 121-141.

McNinch, J. E. (2007), Bar and swash imaging radar (BASIR): A mobile $\mathrm{X}$-band radar designed for mapping nearshore sand bars and swash-defined shorelines over large distances, J. Coastal Res., 23(1), 59-74.

Mitasova, H., M. Overton, and R. S. Harmon (2005), Geospatial analysis of a coastal sand dune field evolution: Jockey's Ridge, North Carolina, Geomorphology, 72, 204-221.

Murray, A. B. (2007), Two paradigms in landscape dynamics: Selfsimilar processes and emergence, in Nonlinear Dynamics in Geophysics, edited by A. A. Tsonis and J. B. Elsner, pp. 15-35, Springer, New York.

Nievergelt, Y. (1999), Wavelets Made Easy, 297 pp., Birkhäuser, Boston, Mass.

Pelletier, J. D. (1999), Self-organization and scaling relationships of evolving river networks, J. Geophys. Res., 104(B4), 7359-7375.

Ruessink, B. G., G. Coco, R. Ranasinghe, and I. L. Turner (2007), Coupled and noncoupled behavior of three-dimensional morphological patterns in a double sandbar system, J. Geophys. Res., 112, C07002, doi:10.1029/2006JC003799. 
Schupp, C. A., J. E. McNinch, and J. H. List (2006), Nearshore shore-oblique bars, gravel outcrops, and their correlation to shoreline change, Mar. Geol., 233, 63-79.

Slott, J. M., A. B. Murray, A. D. Ashton, and T. J. Crowley (2006), Coastline responses to changing storm patterns, Geophys. Res. Lett., 33, L18404, doi:10.1029/2006GL027445.

Solow, A. (2005), Power laws without complexity, Ecol. Lett., 8, 361-363.

Sonu, C. J. (1973), Three-dimensional beach changes, J. Geol., 81, 42-64.

Sornette, D. (2006), Critical Phenomena in Natural Sciences: Chaos, Fractals, Selforganization and Disorder: Concepts and Tools, 528 pp., Springer, New York.

Southgate, H. N., and I. Möller (2000), Fractal properties of coastal profile evolution at Duck, North Carolina, J. Geophys. Res., 105(C5), 11,489-11,507.

Stockdon, H. F., A. H. Sallenger, J. H. List, and R. A. Holman (2002), Estimation of shoreline position and change using airborne topographic lidar data, J. Coastal. Res., 18, 502-513.

Tebbens, S. F., S. M. Burroughs, and E. E. Nelson (2002), Wavelet analysis of shoreline change on the Outer Banks of North Carolina: An example of complexity in the marine sciences, Proc. Natl. Acad. Sci. U. S. A., 99, suppl. 1, 2554-2560.

Thom, B. G., and W. Hall (1991), Behaviour of beach profiles during accretion and erosion dominated periods, Earth Surf. Processes Landforms, 16, 113-127.
Valvo, L. M., A. B. Murray, and A. Ashton (2006), How does underlying geology affect coastline change? An initial modeling investigation, J. Geophys. Res., 111, F02025, doi:10.1029/ 2005JF000340.

Werner, B. T., and T. M. Fink (1993), Beach cusps as self-organized patterns, Science, 260, 968-971.

White, S. A., and Y. Wang (2003), Utilizing DEMs derived from LIDAR data to analyze morphologic change in the North Carolina coastline, Remote Sens. Environ., 85, 39-47.

Zeigler, J. M., C. R. Hayes, and S. D. Tuttle (1959), Beach changes during storms on outer Cape Cod, Massachusetts, J. Geol., 67, 318-336.

A. D. Ashton, Department of Geology and Geophysics, Woods Hole Oceanographic Institution, 3609 Woods Hole Road, MS 22, Woods Hole, MA 02543, USA.

E. D. Lazarus, School of Earth and Ocean Sciences, Cardiff University, Main Building, Park Place, Cardiff CF10 3AT, UK. (LazarusED@cf.ac.uk)

A. B. Murray, Division of Earth and Ocean Sciences, Nicholas School of the Environment, Center for Nonlinear and Complex Systems, Duke University, 103 Old Chemistry Building, Box 13 90227, Durham, NC 27708, USA. 